\title{
Challenges of Development Control in Kampala Capital City, Uganda
}

\author{
John Berch Barugahare \\ Department of Architecture and Physical Planning, School of the Built Environment, \\ Makerere University, Uganda.
}

\begin{abstract}
This paper focuses on Development control tools that are applied to operationalize implementation of urban physical plans in Kampala Capital City, Uganda. This is based on a case study carried out in three Administrative Parishes of: Buziga in Makindye Division; Kazo-Angola in Kawempe Division and Nakasero IV in Central Division all in Kampala Capital City. The study identifies and examines the operational tools applied in the development control processes, their strengths and weaknesses in operationalizing plans implementation. It also goes further to suggest appropriate ways on how these tools can be tailored to effective implementation of the City physical plans.
\end{abstract}

Keywords. Development control, Instrument, Physical development plans, Parish, Division.

DOI: $10.7176 / \mathrm{JEES} / 9-4-10$

Publication date: April $30^{\text {th }} 2019$

\section{Introduction.}

Development control is essentially part of the overall planning process applied as an instrument to operationalize the implementation of urban physical plans to achieve set goals and objectives of the plan. Keith (1977) adds that development control is a system of issuing permits for land use development. Furthermore, Levy (1991) states that these are instruments or tools aimed at ensuring that the designed plans are implemented and conform to the planned land use pattern. These development control tools may be grouped into two broad categories that include, one; the public capital investment that influence the type and location of land uses. The control instruments include, roads, water, Schools, recreation facilities. The second covers the land use controls which include 'zoning' in which are specified plot sizes (maximum and minimum) as by the designed uses; building setbacks as by frontage, sides, back; development coverage; parking and driveway specifications; restrictions or requirements on building that include number of stories (maximum and minimum height), floor area (FAR) and use to which the building is put to as by the type of zone, and change of use.

In the case of Kampala Capital City these development controls are scattered in various statutory documents. Some are in The National Physical Planning Act 2010 that has many elements derived from Kampala Planning Ordinance 1930, Town and Country Planning Act 1948, Town and Country Planning Ordinance 1952, The Town and Country Planning Act 1964. There is then the Building Control and Development Act 2013; The National Environment Act Cap 150. There also exists Kampala Capital City Act. 2011 and the current 'Kampala Capital City Physical Development Plan 2012'.

In the main, development control is operationalized at the local level in this case the 'zone' or 'village'. The principle is that development control is informed by the tools defined at higher level which is the Parish. The tools at the Parish are informed by those at Division and then the City wide level as indicated in Fig.1.

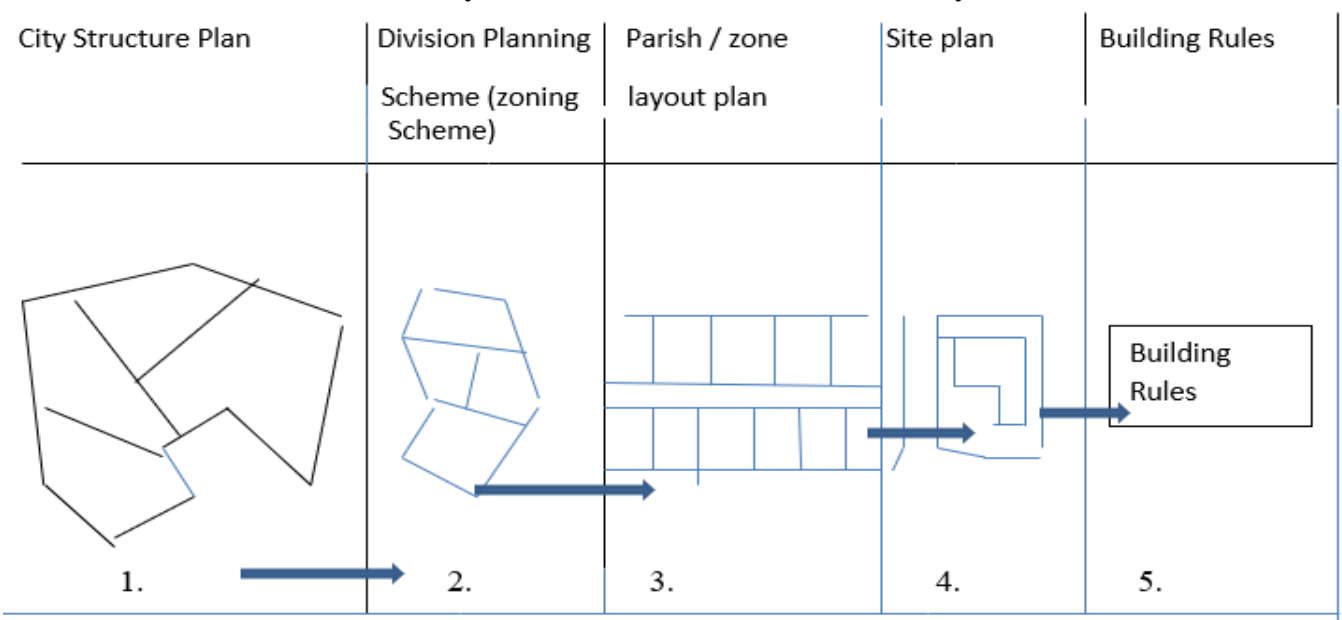

Figure .1: Development Control process

Source: Development Control process as identified by Researcher, 2015. 


\section{Objectives of the study}

This study which is part of the wider $\mathrm{PhD}$ research on 'Development Control and Plans Implementation in Kampala Capital City' has the following objectives:

a) Identify the existing urban development control tools in practice.

b) Examine the problems and constraints of development control tools in operationalizing the physical plans implementation.

d) Recommend policy actions for better operationalization of urban plans implementation

\section{Methods of investigation}

This investigation which is a 'case study' of three administrative parishes of Kazo-Angola (Kawempe Division); Nakasero IV (Central Division) and Buziga (Makindye Division), uses a mixed method of investigation. This is qualitative and quantitative inquiry. Some qualitative data is numerically translated into quantitative format to give more meaning of the findings.

The qualitative data methods used include:

i) Observations of the existing development in the three case study Divisions,

ii) Literature / documents review on development control and other related research works,

iii) Surveys that included at detailed investigations; interviews and use of questionnaires with the target group who were developers,

iv) Discussion with Focus group that were knowledgeable with development issues in the case study divisions

The quantitative data methods included:

i) Analysis of the qualitative data and translating it into numerical form

ii) Generating tables and bar-charts to show the real magnitude of existing nature of development.

The qualitative methods of data collection included: field observations; literature / documents review; surveys that included, interviews and use of questionnaires; focus group discussions and data analysis.

\section{Findings}

The challenges identified are based on the objectives that have been stated. The first objective was to identify the existing development control tools applied in practice. Two types of major development control are identified that include the public capital investment and then the 'Zoning' in order of type of land use and spatial location. Each of these major controls has a number of secondary tools that make them to operationalize implementation of the designed urban plans. These include the designed standards of roads, water systems, space sizes of schools land requirements, community open recreational spaces and other lee ways for other infrastructure as drainage, power and communication channels.

The second is direct land use control which has the major user clause of 'Zoning'. Zoning as by activity user is effected using controls of: plot sizes (maximum and minimum), building setbacks for sides, front and back; development coverage as by development density and major land use type; parking and driveway specifications.

The third major control is 'Building heights' which is also effected by restricted number of stories, floor area ratio (FAR), the use to which the structure can be put to and occupancy rate (number of people that can occupy a building depending on size and use).

The second objective is to examine the challenges and constraints of development control tools in operationalizing physical plans implementation. The research study reveals that the control tools do not address most of the key present day development requirements. For instance the development standards are high and are informed by the 1948 Town and Country Planning Act, and 1951 Kampala Town Planning Ordinance that are carried forward in successive city development plans and National Planning Acts. Particular cases identified include: large plots and other space sizes for different activity users as indicated in Table 1 and Table 2. 
Table 1: Selected Development Control Standards, 1994-2004.

\begin{tabular}{|c|c|c|c|}
\hline 1972-2004 & Land use & Plot size (sq. m) & Plot Development coverage $(\%)$ \\
\hline & 1. Low Density Residential & $1000-1500$ & $15-25$ \\
\hline & 2. Medium Density & $600-1000$ & $20-40$ \\
\hline & 3. High Density Residential & Not less than 200 & $40-70$ \\
\hline & 4. Housing Estate & & $40-70$ \\
\hline & 5.. Commercial & 450 Minimum & $70-90$ \\
\hline & 6. Light industry & 450 & \\
\hline & 7. Medium industry & $900-1200$ & $80-70$ \\
\hline & $\begin{array}{l}\text { 8. Roads } \\
\text { - Primary Distributor } \\
\text { - Secondary Distributor } \\
\text { - Local Distributor } \\
\text { - Access road }\end{array}$ & $\begin{array}{l}\text { Reserve width in Meters } \\
30-40 \\
25-30 \\
25 \\
15-20\end{array}$ & \\
\hline & $\begin{array}{l}\text { 9. Footpath } \\
\text { Cycle lane }\end{array}$ & $\begin{array}{l}2.0 \\
3.0\end{array}$ & \\
\hline & $\begin{array}{l}\text { 10. Social services } \\
\text { - Secondary School } \\
\text { - Primary School } \\
\text { - Nursery School }\end{array}$ & $\begin{array}{l}2.0-6.0 \mathrm{Ha} \\
1.0-3.0 \mathrm{Ha} \\
0.15 \mathrm{Ha}\end{array}$ & \\
\hline & $\begin{array}{l}\text { - Health Centre } 1 \text { and } 2 \\
\text { - Hospital }\end{array}$ & $\begin{array}{l}0.25 \mathrm{Ha} \\
4.0-6.0 \mathrm{Ha}\end{array}$ & \\
\hline
\end{tabular}

Source: Kampala Structure Plan Report 1994-2004

Table 2: Standards of selected uses from the National Physical Planning Standards and Guidelines, 2011.

\begin{tabular}{|l|l|l|l|l|}
\hline Residential Development & Low Density & $\begin{array}{l}\text { Medium } \\
\text { Density }\end{array}$ & $\begin{array}{l}\text { High } \\
\text { Density }\end{array}$ & $\begin{array}{l}\text { High Density Semi- } \\
\text { detached }\end{array}$ \\
\hline Plot area (sq.) & $1000-2000$ & $600-1000$ & $300-600$ & $200-300$ \\
\hline Minimum plot width (m) & 25.0 & 20.0 & 12.0 & 12.0 \\
\hline Minimum plot length (m) & 40.0 & 30.0 & 25.0 & 25.0 \\
\hline Maximum plot coverage & $20 \%$ & $40 \%$ & $40 \%$ & $50 \%$ \\
\hline Minimum building line (m) & $6.0 \mathrm{~m}$ & $6.0 \mathrm{~m}$ & $3.0 \mathrm{~m}$ & $3.0 \mathrm{~m}$ \\
\hline a. Front & $3.0 \mathrm{~m}$ & $2.0 \mathrm{~m}$ & $2.0 \mathrm{~m}$ & $2.0 \mathrm{~m}$ \\
\hline b. side. & $12.0 \mathrm{~m}$ & $8.0 \mathrm{~m}$ & $2.0 \mathrm{~m}$ \\
\hline c. Rear & $3.0 \mathrm{~m}$ & $3.0 \mathrm{~m}$ & \\
\hline d. Servants quarters & $\begin{array}{l}\text { Sewer } \\
\text { sceptic tank }\end{array}$ & $\begin{array}{l}\text { Sewer or sceptic } \\
\text { tank }\end{array}$ & $\begin{array}{l}\text { Sewer or } \\
\text { septic tank }\end{array}$ & Sewer or sceptic tank \\
\hline Sanitation & Piped to house & Piped to house & $\begin{array}{l}\text { Piped to } \\
\text { house }\end{array}$ & Piped to house \\
\hline Water supply &
\end{tabular}

Source: National Physical Planning Standards and Guidelines, 2011.

These standards are found high and beyond the land size areas owned. Research findings indicate smaller sizes of land and this detail is confirmed by the findings of a Land Surveying Firm (Geomaps) as indicated in Table 3.

Table 3: Existing average plot sizes by a sample land uses

\begin{tabular}{|l|l|l|}
\hline Land use & Plot Sizes (Average) & Plot Coverage \\
\hline 1. Commercial & $250-1000$ sq. m & $80-100 \%$ \\
2. Residential & $90-1500$ sq. m & $70-90 \%$ \\
3. Industrial & $450-2000$ sq. m & $70-90 \%$ \\
\hline Type of Roads & Reserves width in Meters & \\
1. Main roads & $25-30 \mathrm{~m}$ & \\
2. Distributor Roads & $10-15 \mathrm{~m}$ & \\
3. Access Roads & $4.0-8.0 \mathrm{~m}$ & \\
\hline
\end{tabular}

Source: Researcher's Field data, 2014.

The statutory standards being high are violated by the developers. This is prevalent in Buziga and KazoAngola that have minimal urban plans. Nakasero VI has more compliance because of the old established statutory detailed plans which provide development control guidelines. 
Research investigations have also revealed that the current land tenure system as provided under the Constitution of the Republic of Uganda constrains development control. Reference here is to customary tenure where the owners do not have legal ownership document which is a 'land title'. In absence of this legal document the City authority cannot receive the building plans. The owners of such lands go ahead and build without permit as they believe they have a right to their land guaranteed by Article 237 (1) under the constitution of The Republic of Uganda 1995. This states that, "Land in Uganda belongs to the citizens Uganda and shall vest in them in accordance with the land tenure system provided in the constitution". Supplementary, this poses another challenge on the public capital investment development control as roads, water, sewer and power lines, health and educational facilities, open spaces and drainage system. These controls influence the quality, intensity and direction of development. Research findings in Kazo-Angola, Buziga Parishes indicate that the land owners where these controls are to be sited are not willing to surrender their lands, and where they are willing the compensation is beyond the ability of the controlling authority and other service providers.

Research findings reveal that the parishes of Kazo-Angola and large parts of Buziga did not have detailed plans to show layout of the land that would guide sitting of buildings and infrastructure. The practice is piecemeal development that is disjointed and does not promote conformance to general land use plans. This is a big challenge to orderly development.

Further research findings indicate that there is lack of awareness on general urban planning and participation in executing the statutory development control tools. Through interviews with Physical Planners at the Divisions and the sampled land developers in the case study parishes, planning and development decisions are still dominated by the technocrats that seek technical solutions to problems and challenges. This follows Keeble's (1983) dictum that 'cities' problems are a technical matter and requiring technical solutions. This philosophical approach has led to exclusion of communities who in turn develop outside the development control requirements. Table 4. shows the number of interviewees' response informed on planning and development control while Table 5. Indicates the level of Participation.

Table 4. Communities being informed on Planning and Development control

\begin{tabular}{|l|c|c|c|c|c|c|}
\hline Does KCCA Keep Community Informed on & \multicolumn{2}{|c|}{ Buziga } & \multicolumn{2}{c|}{ Kazo Angola } & \multicolumn{2}{c|}{ Nakasero IV } \\
\cline { 2 - 8 } Planning and Development control & Freq. & \%age & Freq. & \%age & Freq. & \%age \\
\hline Regularly & 1 & 3.3 & 0 & - & 0 & - \\
\hline Sometimes & 11 & 36.7 & 11 & 29.7 & 1 & 11.1 \\
\hline Never Does & 18 & 60.0 & 26 & 70.3 & 8 & 88.9 \\
\hline & & & & & & \\
\hline Total & $\mathbf{3 0}$ & $\mathbf{1 0 0}$ & $\mathbf{3 7}$ & $\mathbf{1 0 0}$ & $\mathbf{9}$ & $\mathbf{1 0 0}$ \\
\hline
\end{tabular}

Source: Researcher's Field Data, 2014

Table 5: Participation in Planning Process and the type

\begin{tabular}{|l|c|c|c|c|c|c|}
\hline \multirow{2}{*}{ Participation in the planning process and the type } & \multicolumn{2}{|c|}{ Buziga } & \multicolumn{2}{|c|}{ Kazo Angola } & \multicolumn{3}{c|}{ Nakasero IV } \\
\cline { 2 - 7 } & Freq. & \%age & Freq. & \%age & Freq. & \%age \\
\hline Passive Participation & 1 & 3.3 & 5 & 13.5 & 0 & - \\
\hline Participation in information (Questioning) & 1 & 3.3 & 0 & - & 2 & 22.2 \\
\hline Consultation & 5 & 16.7 & 1 & 2.7 & 0 & - \\
\hline Functional Participation & 15 & 50.0 & 14 & 37.8 & 0 & - \\
\hline Interactive Participation & 1 & 3.3 & 0 & - & 0 & - \\
\hline Never Participate & 7 & 23.3 & 17 & 45.9 & 7 & 77.8 \\
\hline & & & & & & \\
\hline Total & $\mathbf{3 0}$ & $\mathbf{1 0 0}$ & $\mathbf{3 7}$ & $\mathbf{1 0 0}$ & $\mathbf{9}$ & $\mathbf{1 0 0}$ \\
\hline
\end{tabular}

Source: Researcher's Field Data, 2014

Lack of communication and participation is exacerbated by decentralised planning where decisions are being taken from the centre. The implementers of development control are merely directed to develop as by the development control requirements (Assistant Town Clerk, Makindye Division, 2013).

Identified is the challenge of delays in processing and approval of applications for development permit. Research findings indicate that processing and getting permit for submitted application takes between 3 to 6 months. In some cases this can go up to 12 months as shown in Table 6. 
Table 6: Duration of Response to development applications

\begin{tabular}{|c|c|c|c|c|c|c|}
\hline \multirow{2}{*}{ Duration of response for inquiries } & \multicolumn{2}{|c|}{ Buziga } & \multicolumn{2}{|c|}{ Kazo Angola } & \multicolumn{2}{|c|}{ Nakasero IV } \\
\hline & Freq. & \%age & Freq. & \%age & Freq. & \%age \\
\hline Less than a week & 0 & - & 6 & 16.2 & 0 & - \\
\hline Six months & 5 & 16.7 & 7 & 18.9 & 0 & - \\
\hline Two months & 1 & 3.3 & 1 & 2.7 & 0 & - \\
\hline Over 12 months & 16 & 53.3 & 17 & 45.9 & 6 & 66.7 \\
\hline Not sure & 8 & 26.7 & 6 & 16.2 & 3 & 33.3 \\
\hline Total & 30 & 100 & 37 & 100 & 9 & 100 \\
\hline
\end{tabular}

Source: Researcher's Field Data, 2014

The interviewees highlighted that once there are any delays in getting response from the City Authority, they are forced to bypass the regulatory requirements and build. This simultaneously imposes the challenge to the enforcement of the rules of conformance when development has already taken place.

There is also the challenge of the existing institutional framework where various institutions or statutory bodies involved in executing development instruments as roads, piped water, power lines do not integrate their facilities sectoral plans in the overall City Physical Development Plans. This is identified as a challenge of using overlapping different laws which make it problematic to the Authority's enforcement. Most of these provide their facilities to individuals depending on individual developers' ability to pay. In the process the developers defy the city development control plans. Closely linked to uncoordinated execution of development control instruments is the issue of having many actors who are council officers and local areas officials involved in guiding developers in implementing development control tools as indicated in Table 7.

Table 7: Many Actors involved in guiding Planning and Development control.

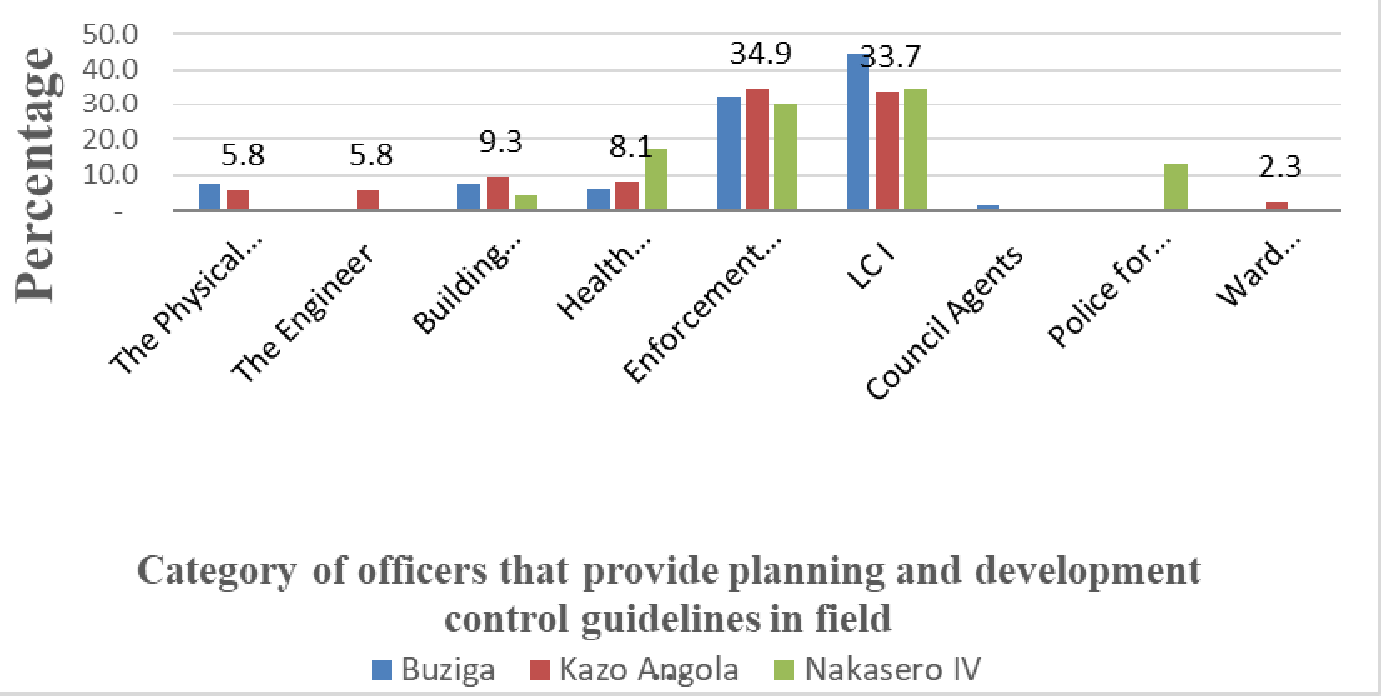

Source: Researcher's field data, 2014

The many actors often do the same things and end up confusing the public, and this has been found to create room for compromise and corruption in form of bribery. This confusion of the public confirms what Davis, 2001 calls 'opening door to bribery and corruption'. Consequently corruption practices pose a challenge to development control effectiveness. This also brings out the factor identified in the field that the least informed personnel on planning and development control mechanisms that include local council (L.C 1) and Enforcement are the ones on the forefront of guiding the developers.

Another critical challenge is inadequacy of professional qualified staff involved in planning and development control tasks. At the time of the investigation each of the Divisions where the case study parishes are located had one urban planner each. The minimum expected in each Division is 2 planners with support staff. This inadequacy of urban planners resulted in inadequacy of monitoring development control processes in the field to ensure compliance.

Low funding for Physical Planning Directorate as highlighted in Table 8 has constraints on planning and development control activities. This poses serious limitations on preparation of areas' local detailed plans, an important development control tool. Similarly, this constrains availability of logistical materials as computers and requisite design programs; field vehicles specifically assigned to planning for regular field work and monitoring and limitations on funding public awareness programs in the media and field. 
Table 8: Budgetary allocations for KCCA Activities for FY 2012/2013

\begin{tabular}{|l|l|r|}
\hline No & Activities & Amount Allocated (UGX) \\
\hline 1. & Administration and Human Resources & $31,761,799,000$ \\
\hline 2. & Legal & $1,915,102,000$ \\
\hline 3. & Treasury & $2,944,076,000$ \\
\hline 4. & Internal Audit & $50,000,000$ \\
\hline 5. & Political Governance & $18,153,000$ \\
\hline 6. & Executive support & $2,016,642,000$ \\
\hline 7. & Revenue collection and Mobilization & $5,343,378,000$ \\
\hline 8. & Engineering and Technical Services & $46,103,821,000$ \\
\hline $\mathbf{9 .}$ & Physical Planning & $\mathbf{1 , 0 6 2 , 0 0 0 , 0 0 0}$ \\
\hline 10. & Gender, Production, Community Services & $4,209,749,420$ \\
\hline 11. & Education and Social Services & $6,739,736,000$ \\
\hline & TOTAL & $\mathbf{1 6 2 , 5 7 6 , 8 5 2 , 5 9 0}$ \\
\hline
\end{tabular}

Source: Ministerial Policy Statement Vote 122 KCCA FY 2012/2013 Report.

\section{RECOMMENDATIONS AND CONLUSION}

A number of challenges that face the existing development control tools in their application to effectively operationalize urban plans implementation have been highlighted. These include: tools not addressing realities on the ground, land tenure system, lack of area / local detailed plans, lack of public awareness, participation and communication on planning and development control, delays in plans processing and approvals, existing institutional framework and the many actors in the field involved in providing guidance in planning and development control, inadequacy of skilled staff, monitoring and inadequate funding of planning and development control.

The following recommendations are put forward to minimize the highlighted challenges impact and cause effective operationalization of the city physical plans implementation. These include:

a) . It is recommended that the various plot sizes for different users be revisited, and including those space sizes for various types of public facilities and physical infrastructure. The standards need to be in consonance with what the communities can afford in tandem with their interests and economic affordability. These have to promote inclusiveness whereby each individual and other types of activities can locate where they fit. Overlooking the fore stated is likely to lead to the continued defiance of the development control tools. This review is exigent and needs to be carried out by The City Authority and the National Physical Planning Board. While this process may take some time, the City Authority can work out provisional Development control standards which the National Physical Planning Board could approve while waiting for the long term development control measures. It is also recommended that Kampala City Authority discusses with the National Physical Planning Authority in having its own development control standards to address its unique development situation.

b). The issue of land tenure system from the vintage of ownership needs to be addressed as has been identified to pose constraint to effecting development control tools on the ground. The land owners are reluctant to surrender land for communication channels and recommended plot sizes. Hence this requires negotiations between the land owners and the City Authority to reach consensus on appropriate strategy of applying the development control tools to facilitate planned implementation of urban plans.

c). There is also need to intensify public awareness and participation of communities and other interests in planning and development control processes. Research findings in the study areas indicated that the majority of interviewees were not informed about planning nor the tools for development control which also led to minimal participation. This also revealed that there was minimal communication to the communities and other parties. Therefore the stated issues need to be undertaken at the various stages of development control that include: divisions, parishes and zones where actual implantation takes place.

d). It is also recommended that with issues of accessing land and public awareness handled, the strategy should be to prepare local area detailed plans. These are essentially 'development control plans' and an important instrument in operationalizing implementation of urban plans. In cases of those areas that may not have immediate detailed plans prepared, 'piece meal meal' planning should continue. This should be consciously done so that the planned plots and infrastructure can be integrated in the large areas' detailed plans.

e). Delays in processing development applications and responding to other development inquiries are identified as a critical challenge. The interviews has revealed that time of waiting ranges between 3 to 6 months and at times extending to 12 months. The developers are found not to wait for so long and hence go along and develop illegally without any the development control guidelines. The City Authority needs to revisit the procedures and make them shorter and consequently provide quick response. In this respect also the number of 
check points in City Hall need to be reduced. Interviewees indicated that there is 'Fear of City Hall' and hence most communities keep back and develop risking harsh punitive actions of the enforcement officers.

f). Furthermore the City Authority has to coordinate the different Agencies' utilities provision in the city. The utility plans have to be integrated in the overall city spatial plans. The utilities are important development controls that influence the pattern and direction of development. Similarly, the numbers of Actors in the field need to be reduced. These are found to duplicate the work and end up confusing the developers who in turn defy the development control tools.

Many actors in the field are also found to promote compromise on the development control tools in form of bribery which is corruption as revealed by research findings.

g). Inadequate skilled capacity to execute effectively development control requirements is revealed by the research findings. In the study areas it was established that there is one urban planner in each Division and yet a minimum of three urban planners per Division would be required as indicated by Kawempe Division Principal Assistant Town Clerk, Kampala Capital City Authority (2013). The consequence is ineffective guidance and monitoring of application of development control tools in operationalizing implementation of urban plans. Hence in absence of adequate skilled planners and other relevant staff, then lack of monitoring developers continue to develop outside the development control requirements. The City Authority needs to increase the number of Planners to minimum of three per Division and follow up the issue of regular monitoring to ensure guidance and compliance.

h). Funding of urban planning and development control activities is identified as being low compared to the budgetary provisions of other Directorates within the Authority Even within the Directorate of Physical Planning, Landscape Unit gets more money than Physical Planning. This incapacitates the activities of the later with development control affected most. The City Authority should increase the budget of planning taking into account that the former is a prerequisite for orderly and sustainable development of the city.

\section{CONCLUSION}

Development control is a very important process of the whole planning spectrum as it operationalizes implementation of urban plans. It is therefore imperative that the tools of development control are appropriately applied and in consonance with the individuals and other interested parties desires. This is so if the developments being implemented have to be in the frame work of the designed spatial plans. This is to be achieved if the challenges pointed out are addressed with commitment by Kampala Capital City.

\section{REFERENCES}

1. Cullingworth, J.B (1983): Town and Country Planning in Britain, $8^{\text {th }}$ Edition, Allen \& Unwin.

2. Davas, N. (2001): Does City Governance matter for the urban poor? International Planning Studies, 6 (4), $393-408$

3. Keith, T. (1997): Development Control Principles and Practice, University College London Press Limited, U.K.

4. Levy, N.J (1991): Contemporary Urban Planning, Second Edition, Prentice Hall, Englewood Cliffs, N.J.

5. Ministry of Local Government, Uganda (2010): Urban Situational Analysis in Uganda: Report. National Urban Policy Development Support. Pp70-72, 77.

6. Ngetich,J.K; Opala,G.P.; Mulongo, L.S. (2014): A Study on the effectiveness of urban development control Instruments and Practices in Eldoret Municipality, Kenya. Journal of Emerging Trends in Engineering and Applied Sciences, 5(2) :83-91.

7.. Rakodi, C. (2000): Forget Planning, put politics first? Priorities for urban management in Developing countries. I.T.C Journal, Issue 3, 2001. 